\title{
Vitamin D status and 3-month Glasgow Outcome Scale scores in patients in neurocritical care: prospective analysis of 497 patients
}

\author{
Jian Guan, MD, ${ }^{1}$ Michael Karsy, MD, PhD, ${ }^{1}$ Andrea A. Brock, MD, MSCI, ${ }^{1}$ llyas M. Eli, MD, \\ Gabrielle M. Manton, APRN, ${ }^{1}$ Holly K. Ledyard, MD, MS, ${ }^{2}$ Gregory W. J. Hawryluk, MD, PhD, ${ }^{1}$ and \\ Min S. Park, MD1
}

Departments of ${ }^{1}$ Neurosurgery and ${ }^{2}$ Neurology, Clinical Neurosciences Center, University of Utah, Salt Lake City, Utah

\begin{abstract}
OBJECTIVE Vitamin D deficiency has been associated with a variety of negative outcomes in critically ill patients, but little focused study on the effects of hypovitaminosis $D$ has been performed in the neurocritical care population. In this study, the authors examined the effect of vitamin D deficiency on 3-month outcomes after discharge from a neurocritical care unit (NCCU).
\end{abstract}

METHODS The authors prospectively analyzed 25-hydroxy vitamin D levels in patients admitted to the NCCU of a quaternary care center over a 6-month period. Glasgow Outcome Scale (GOS) scores were used to evaluate their 3-month outcome, and univariate and multivariate logistic regression was used to evaluate the effects of vitamin $D$ deficiency.

RESULTS Four hundred ninety-seven patients met the inclusion criteria. In the binomial logistic regression model, patients without vitamin D deficiency (> $20 \mathrm{ng} / \mathrm{dl}$ ) were significantly more likely to have a 3-month GOS score of 4 or 5 than those who were vitamin D deficient (OR 1.768 [95\% Cl 1.095-2.852]). Patients with a higher Simplified Acute Physiology Score (SAPS II) (OR 0.925 [95\% Cl 0.910-0.940]) and those admitted for stroke (OR 0.409 [95\% Cl 0.209-0.803]) or those with an "other" diagnosis (OR 0.409 [95\% Cl 0.217-0.772]) were significantly more likely to have a 3-month GOS score of 3 or less.

CONCLUSIONS Vitamin D deficiency is associated with worse 3-month postdischarge GOS scores in patients admitted to an NCCU. Additional study is needed to determine the role of vitamin D supplementation in the NCCU population.

https://thejns.org/doi/abs/10.3171/2017.2.JNS163037

KEY WORDS Glasgow Outcome Scale; hypovitaminosis; multivariable analysis; prospective study; risk factors; vitamin D; traumatic brain injury

$\mathrm{V}$ ITAMIN D is a fat-soluble vitamin found in the human diet and derived from dermal synthesis..$^{25}$ Its primary clinical function in human health is to support calcium homeostasis and bone metabolism..$^{23}$ Recognition of its pleiotropic effects in modulating immune and other cellar functions has increasingly been the central topic of an expanding body of literature. ${ }^{11}$

Vitamin D deficiency, or hypovitaminosis D, a prevalent problem in the general population, is associated with a higher mortality rate and poorer outcomes in critically ill populations. ${ }^{30}$ The majority of studies performed have concerned the association of vitamin D levels and various critical and chronic illnesses, and much of the focus has been on generalized intensive care populations. Because the results of recent studies indicate that vitamin D might have neuroprotective attributes, ${ }^{14,27}$ links between hypovitaminosis D and critically ill patients with a neurological condition might necessitate altering treatment plans to improve outcomes in this population.

The results of a recent study that focused on the influence of hypovitaminosis D on the in-hospital mortality rate in a specialized neurocritical care unit (NCCU) suggest an association between vitamin D deficiency on admission and worse outcomes within this unique population. ${ }^{8}$ Although the results of several studies also suggest that the effects of hypovitaminosis D on patient outcome extend beyond the hospitalization itself, ${ }^{3,12}$ a paucity of data on the relationship between vitamin D status on ad-

ABBREVIATIONS BMI = body mass index; GOS = Glasgow Outcome Scale; NCCU = neurocritical care unit; SAPS II = Simplified Acute Physiology Score .

SUBMITTED December 2, 2016. ACCEPTED February 9, 2017.

INCLUDE WHEN CITING Published online August 11, 2017; DOI: 10.3171/2017.2.JNS163037. 
mission and postdischarge outcomes in neurocritical care patients exists. We prospectively studied the association between hypovitaminosis $\mathrm{D}$ on admission and 3-month postdischarge outcome of patients in a quaternary NCCU.

\section{Methods \\ Study Population}

After receiving approval from the University of Utah Institutional Review Board, which included a waiver of informed consent, data on 25-hydroxy vitamin D levels and other patient variables were gathered prospectively using a combination of clinical examination, review of radiological films, and evaluation of medical records. Each patient admitted to the NCCU (latitude $40.7717^{\circ}$ north) between September 1, 2015, and February 29, 2016, was eligible for enrollment in the study. Patients routinely undergo serum vitamin D (25-hydroxy vitamin D) evaluation. Patients were excluded if they were younger than 18 years at the time of admission, admitted under a service other than neurosurgery or neurology because of hospital intensive care bed needs, or unable to undergo vitamin $\mathrm{D}$ testing within 24 hours of admission to the NCCU. Patients who did not return to the clinic for evaluation 3 months after discharge were also excluded, because Glasgow Outcome Scale (GOS) scores in these patients could not be calculated without clinical follow-up. Patients who were readmitted to the NCCU before discharge were not dually enrolled.

\section{Data Collection}

Baseline demographic information, including age, sex, body mass index (BMI), and race/ethnicity, was obtained when available. Patient insurance type was recorded as private, Medicaid/self-pay, or Medicare. Medicaid is the US program designed to provide health insurance to people with low income, although eligibility requirements for coverage vary according to state. Medicare is the US program designed to provide health insurance for elderly people (defined as those aged 65 years or older), people with various disabilities, and those with certain medical conditions, such as end-stage renal disease or amyotrophic lateral sclerosis (https://www.medicare.gov). Each patient was assessed also for the presence of hypertension and diabetes and active use of tobacco, alcohol, and illicit drugs. Admission information for each patient, including whether surgical intervention was performed immediately before or during the NCCU admission and whether the admission was elective or emergent, was recorded. Patients considered to have been electively admitted include those who were scheduled for NCCU admission $>1$ week before arrival in the NCCU, including those admitted for a prearranged cranial or spine procedure or planned diagnostic testing. Each admission diagnosis was placed into 1 of 4 categories: postoperative care, stroke (hemorrhagic or ischemic), trauma, or other. The 3 most common diagnoses under each category were craniotomy for resection of tumor, transsphenoidal resection of pituitary tumor, and endovascular treatment of unruptured intracerebral aneurysm (postoperative); traumatic subarachnoid hemorrhage, traumatic acute subdural hematoma, and traumatic cerebral contusions (trauma); ischemic stroke, hyperten- sive intraparenchymal hemorrhage, and aneurysmal subarachnoid hemorrhage (stroke); and status epilepticus, chronic subdural hematoma, and encephalopathy (other). Preadmission vitamin D supplementation, defined as daily supplemental intake $>500 \mathrm{U}$, was also recorded. Patients who were taking vitamin D supplementation before hospitalization were not continued on supplementation as inpatients, although those who were found to be deficient in vitamin $\mathrm{D}(<20 \mathrm{ng} / \mathrm{ml})$ were treated using 50,000 U of vitamin $\mathrm{D}_{2}$ (ergocalciferol) administered orally or via feeding tube weekly, per hospital protocol.

To aid in controlling for illness severity, we calculated a Simplified Acute Physiology Score (SAPS II) for each patient. This score is an assessment of 17 physiological, demographic, and hospitalization-specific factors derived from an international sample of patients and validated as an indicator of risk of death for each patient during hospitalization..$^{15}$ The SAPS II has been shown to be associated with death in patient populations similar to that used in our study, 9,19,20,28 and according to established guidelines, all scores were calculated within 48 hours of admission.

25-Hydroxy vitamin D levels, assessed using a chemiluminescence immunoassay (the Diasorin LIAISON system), were obtained within 24 hours of NCCU admission in all included patients. Other laboratory results recorded as part of standard NCCU care were serum calcium and phosphate levels. These results were also collected within 24 hours of NCCU admission and were dichotomized into 2 groups (high or low) based on reference values $(9.35 \mathrm{mg} /$ $\mathrm{dl}$ [calcium] and $3.25 \mathrm{mg} / \mathrm{dl}$ [phosphate]). ${ }^{21}$ Because of the association between renal disease and vitamin $\mathrm{D}$ deficiency, likely a result of the important role the kidneys play in vitamin D homeostasis, ${ }^{1}$ each patient had a glomerular filtration rate calculated based on serum creatinine level measured within 24 hours of admission. ${ }^{16}$ For instances in which more than 1 laboratory value was obtained, the value measured closest to the time of NCCU admission was used. The phosphate level was missing for 6 patients, and the median phosphate value $(3.3 \mathrm{mg} / \mathrm{dl})$ was substituted in all analyses for these patients.

The primary outcome for this study was the patient's 3-month GOS score as assessed during follow-up visits in the neurosurgery or neurology clinic (Fig. 1). A score of 1 corresponds to death, 2 to a persistent vegetative state (unable to interact with the environment and unresponsive), 3 to severe disability (able to follow simple commands but unable to perform acts of daily living to the point of living independently), 4 to moderate disability (able to live independently but unable to return to work or school without special assistance), and 5 to low disability (minimal neurological or psychological deficit). ${ }^{13}$ For this study, GOS scores were dichotomized into a score of $1-3$ or $4-5$. No formal blinding of those who assessed the GOS scores and vitamin D levels was performed. Secondary outcome measures included ventilator duration, NCCU length of stay, and hospital length of stay. Any development of urinary tract infection, pneumonia, or sepsis during the hospital stay was also recorded. In all cases, infection was defined as culture-positive evidence of infection that required treatment with antibiotic therapy. 


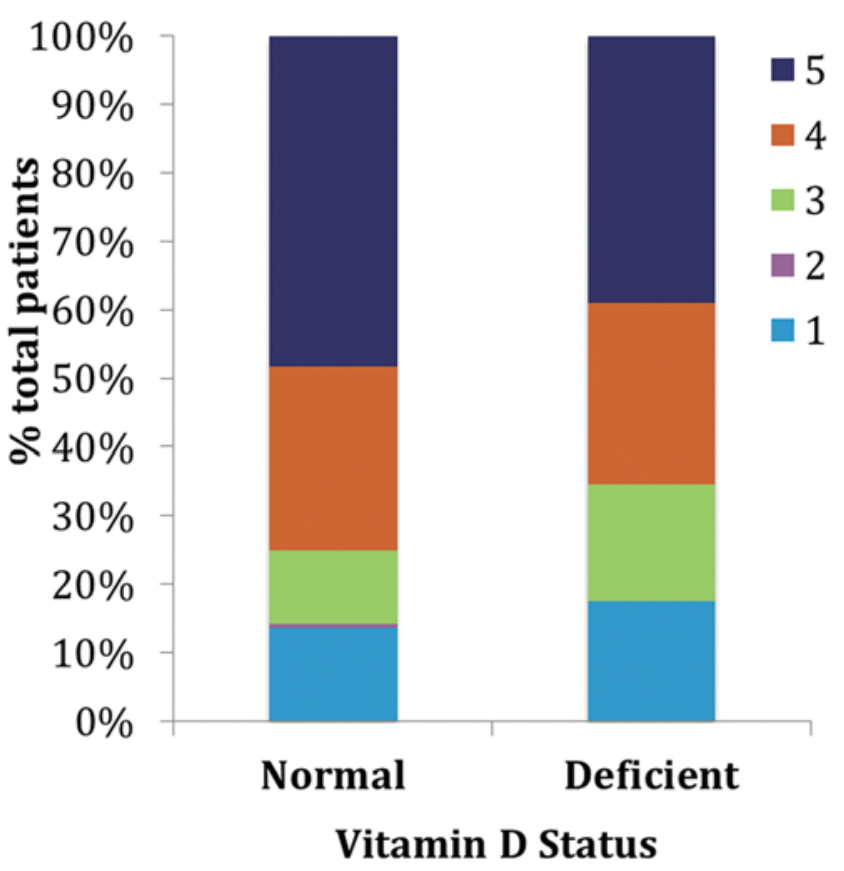

FIG. 1. Three-month GOS scores according to vitamin D status. Figure is available in color online only.

\section{Statistical Analysis}

Continuous variables in all cases were analyzed using the Student t-test, and categorical variables were analyzed using $\chi^{2}$ analysis. Univariate analysis was performed for vitamin $\mathrm{D}$ status after dichotomization into the vitamin D-deficient (25-hydroxy vitamin D level $\leq 20 \mathrm{ng} / \mathrm{ml}$ ) or vitamin D-sufficient (25-hydroxy vitamin D level > $20 \mathrm{ng} / \mathrm{ml}$ ) group according to previously published cutoffs. ${ }^{18,26}$ A separate univariate analysis using a cutoff of $\leq$ $12 \mathrm{ng} / \mathrm{ml}$ was performed to evaluate the effects of severe vitamin $\mathrm{D}$ deficiency, again according to previously published cutoffs. ${ }^{2}$

Univariate analysis was performed also on 3-month GOS scores after dichotomization into scores of 1-3 or $4-5$. Variables with a $p$ value of $<0.2$ in univariate analysis of GOS scores were included in a forward, stepwise, binomial logistic regression model with an entry cutoff of 0.05 and a removal cutoff of 0.10 . Age was not included in our multivariable model, despite having a $\mathrm{p}$ value of $<$ 0.2 in univariate analysis, because it is a component of the SAPS II. Mean values are presented \pm SD.

\section{Results}

Of 888 unique admissions to the NCCU during the study period, 497 met criteria for inclusion. Of these patients, 296 (33.3\%) were excluded because they did not present for follow-up in the clinic 3 months after discharge, $43(4.8 \%)$ were excluded because they were admitted to a non-neurology/neurosurgery service, $7(0.8 \%)$ were excluded for admission at $<18$ years of age, $15(1.7 \%)$ were excluded for having not had a 25-hydroxy vitamin D level measured within 24 hours of admission, and 30 (3.4\%) were excluded for readmission during the same hospitalization. Patients who died before their 3-month follow-up visit were included with a GOS score of 1 .

Of the patients who met the inclusion criteria, 182 (36.6\%) were vitamin D deficient at the time of hospitalization. In univariate analysis, vitamin D-deficient patients were younger (mean age $49.5 \pm 16.4$ vs $58.0 \pm 17.9$ years; $p<0.001)$ (Table 1 ), were more likely to actively use tobacco $(22 \%$ vs $13 \%$; $\mathrm{p}=0.009)$, were less likely to be taking preadmission vitamin D supplementation (7.1\% vs $31.1 \%$; $\mathrm{p}<0.001)$, and had a higher BMI $(29.2 \pm 7.0$ vs $\left.27.9 \pm 6.1 \mathrm{~kg} / \mathrm{m}^{2} ; \mathrm{p}=0.035\right)$. Vitamin D-deficient patients were also less likely to have a high calcium level $(10.4 \%$ vs $17.8 \% ; p=0.028)$, more likely to be on Medicaid or be a self-payer $(26.4 \%$ vs $11.7 \%$; $\mathrm{p}<0.001)$, and less likely to be Caucasian $(79.1 \%$ vs $88.3 \%$; $\mathrm{p}=0.030)$. Vitamin $\mathrm{D}-$ sufficient patients were significantly less likely to require readmission within 30 days of hospital discharge $(9.5 \%$ vs $13.7 \%$; $p=0.014)$. At the 3 -month follow-up visit, vitamin D-deficient patients were significantly more likely to have a lower GOS score (1-3) than vitamin D-sufficient patients $(34.6 \%$ vs $25.1 \% ; \mathrm{p}=0.023)$.

Fifty-nine patients (11.9\%) in our cohort met criteria for severe vitamin D deficiency. In our univariate analysis, severely deficient patients were significantly younger (mean age $48.9 \pm 15.2$ vs $55.7 \pm 18.0$ years; $p=0.006$ ) (Table 2 ), were more likely to actively use tobacco (39\% vs $13.2 \%$; $\mathrm{p}<0.001$ ), were less likely to be taking preadmission vitamin D supplementation (3.4\% vs $24.9 \%$; $p<0.001)$, and had a higher BMI $\left(30.8 \pm 9.4\right.$ vs $28.1 \pm 6.0 \mathrm{~kg} / \mathrm{m}^{2} ; \mathrm{p}$ $=0.002)$. Severely deficient patients were more likely to be on Medicaid or be a self-payer $(28.8 \%$ vs $15.5 \%$; $\mathrm{p}=$ $0.002)$ and less likely to be Caucasian $(74.6 \%$ vs $86.3 \%$; $\mathrm{p}=0.004)$. Severely vitamin $\mathrm{D}$-deficient patients had a higher rate of pneumonia during their hospitalization than those who were not severely deficient $(13.6 \%$ vs $5.0 \%$; $p$ $=0.010$ ).

At the 3-month follow-up visit, 142 patients (28.6\%) had a low GOS score $(1,2$, or 3$)$, whereas $355(71.4 \%)$ had a high GOS score (4 or 5). In univariate analysis, patients with a low GOS score were more likely to be older (mean age $60.9 \pm 17.3$ vs $52.5 \pm 17.5$ years; $\mathrm{p}<0.001$ ) (Table 3 ), to have a history of hypertension $(50.7 \%$ vs $40.8 \%$; $\mathrm{p}=$ $0.045)$ or diabetes $(22.5 \%$ vs $12.7 \% ; p=0.006)$, and to not drink alcohol (26.1\% vs $35.2 \%$; $p=0.049)$. Patients with a low GOS score also had a significantly higher SAPS II $(38.3 \pm 16.6$ vs $20.9 \pm 12.2 ; \mathrm{p}<0.001)$, a lower BMI $(27.4$ \pm 6.7 vs $28.8 \pm 6.4 \mathrm{~kg} / \mathrm{m}^{2} ; \mathrm{p}=0.034$ ), and lower glomerular filtration rate $(83.6 \pm 30.5$ vs $89.2 \pm 23.0 \mathrm{ml} / \mathrm{min} / 1.73$ $\left.\mathrm{m}^{2} ; \mathrm{p}=0.027\right)$. Those with a low GOS score were significantly less likely to have a high phosphate level $(38.7 \%$ vs $56.6 \%$; $<0.001)$ and more likely to be deficient in vitamin D (44.4\% vs $33.5 \%$; $\mathrm{p}=0.023)$ than those with a higher 3-month GOS score. The group of those who were admitted to the NCCU postoperatively had a significantly higher rate of high GOS score at the 3-month follow-up visit $(44.5 \%$ vs $14.1 \%$; $p<0.001)$, as did patients with private insurance $(55.5 \%$ vs $36.6 \% ; \mathrm{p}<0.001)$ and Caucasian patients $(86.8 \%$ vs $80.3 \%$; $p=0.045)$. Patients with a low GOS score at the 3-month follow-up visit were more likely to have stayed longer in the NCCU $(5.3 \pm 6.5$ vs $3.2 \pm 4.1$ days; $\mathrm{p}<0.001)$ and in the hospital overall $(9.1 \pm 10.5$ vs 
TABLE 1. Univariate analysis comparing 25-hydroxy vitamin D-deficient with 25-hydroxy vitamin D-sufficient patients

\begin{tabular}{|c|c|c|c|}
\hline Variable & $\begin{array}{c}\text { Deficient } \\
(<20 \mathrm{ng} / \mathrm{ml})^{*}\end{array}$ & Sufficient* & $p$ Value \\
\hline No. of patients & 182 & 315 & \\
\hline Age (yrs) & $49.5 \pm 16.4$ & $58.0 \pm 17.9$ & $<0.001 \dagger$ \\
\hline Sex, female & $77(42.3)$ & $148(47.0)$ & 0.313 \\
\hline Hypertension & $71(39.0)$ & $146(46.3)$ & 0.112 \\
\hline Diabetes & $25(13.7)$ & $52(16.5)$ & 0.411 \\
\hline Tobacco use & $40(22.0)$ & $41(13.0)$ & $0.009 \dagger$ \\
\hline Alcohol use & $61(33.5)$ & $101(32.1)$ & 0.739 \\
\hline Illicit drug use & $14(7.7)$ & $16(5.1)$ & 0.239 \\
\hline Vitamin D supplementation & $13(7.1)$ & $98(31.1)$ & $<0.001 \dagger$ \\
\hline SAPS II & $25.9 \pm 17.2$ & $25.8 \pm 14.9$ & 0.940 \\
\hline $\mathrm{BMI}\left(\mathrm{kg} / \mathrm{m}^{2}\right)$ & $29.2 \pm 7.0$ & $27.9 \pm 6.1$ & $0.035 \dagger$ \\
\hline $\begin{array}{l}\text { Glomerular filtration rate }(\mathrm{ml} / \\
\left.\min / 1.73 \mathrm{~m}^{2}\right)\end{array}$ & $93.4 \pm 25.8$ & $84.3 \pm 24.7$ & $<0.001 \uparrow$ \\
\hline High calcium level & $19(10.4)$ & $56(17.8)$ & $0.028 \dagger$ \\
\hline High phosphate level & $100(54.9)$ & $156(49.5)$ & 0.244 \\
\hline Planned admission & $59(32.4)$ & $122(38.7)$ & 0.159 \\
\hline Surgery during NCCU stay & $103(56.6)$ & $200(63.5)$ & 0.129 \\
\hline Insurance type & & & $<0.001 \dagger$ \\
\hline Private & $103(56.6)$ & $146(46.3)$ & \\
\hline Medicaid/self-pay & $48(26.4)$ & $37(11.7)$ & \\
\hline Medicare & $31(17.0)$ & $132(41.9)$ & \\
\hline Admission category & & & 0.422 \\
\hline Postop & $57(31.3)$ & $121(38.4)$ & \\
\hline Trauma & $24(13.2)$ & $36(11.4)$ & \\
\hline Stroke & $48(26.4)$ & $70(22.2)$ & \\
\hline Other & $53(29.1)$ & $88(27.9)$ & \\
\hline \multicolumn{4}{|l|}{ Race/ethnicity } \\
\hline Caucasian & $144(79.1)$ & $278(88.3)$ & $0.030 \dagger$ \\
\hline Hispanic/Latino & $20(11.0)$ & $19(6.0)$ & \\
\hline African American & $3(1.6)$ & $2(0.6)$ & \\
\hline Asian/Pacific Islander & $8(4.4)$ & $3(1.0)$ & \\
\hline Native American & $1(0.5)$ & $1(0.3)$ & \\
\hline Other/unknown & $6(3.3)$ & $12(3.8)$ & \\
\hline Length of NCCU stay (days) & $3.8 \pm 5.2$ & $3.8 \pm 4.9$ & 0.982 \\
\hline Length of hospital stay (days) & $7.2 \pm 8.3$ & $6.4 \pm 6.9$ & 0.262 \\
\hline Ventilator duration (days) & $1.4 \pm 4.0$ & $1.3 \pm 4.9$ & 0.794 \\
\hline Urinary tract infection & $17(9.3)$ & $18(5.7)$ & 0.128 \\
\hline Pneumonia & $14(7.7)$ & $16(5.1)$ & 0.239 \\
\hline Sepsis & $2(1.1)$ & $3(1.0)$ & 0.875 \\
\hline 30-day readmission rate & & & $0.014 \dagger$ \\
\hline No & $135(74.2)$ & $266(84.4)$ & \\
\hline Yes & $25(13.7)$ & $30(9.5)$ & \\
\hline $\begin{array}{l}\text { Death } 30 \text { days after } \\
\text { discharge }\end{array}$ & $22(12.1)$ & $19(6.0)$ & \\
\hline 3-mo GOS score & & & $0.023 \dagger$ \\
\hline $1-3$ & $63(34.6)$ & 79 (25.1) & \\
\hline $4-5$ & $119(65.4)$ & $236(74.9)$ & \\
\hline 3-mo mortality & $32(17.6)$ & $43(13.7)$ & 0.238 \\
\hline
\end{tabular}

» CONTINUED FROM PREVIOUS COLUMN

TABLE 1. Univariate analysis comparing 25-hydroxy vitamin D-deficient with 25-hydroxy vitamin D-sufficient patients

\footnotetext{
* Values represent number (\%) of patients or mean \pm SD.

$\dagger p$ values $<0.05$ were considered significant.
}

$5.7 \pm 5.5$ days; $p<0.001)$, were more likely to have had a prolonged ventilator-dependent period $(2.9 \pm 6.6$ vs $0.7 \pm$ 3.2 days; $p<0.001$ ), and to have developed a urinary tract infection $(12 \%$ vs $5.1 \%$; $=0.007)$ or pneumonia $(13.4 \%$ vs $3.1 \%$; $\mathrm{p}<0.001$ ) during their stay.

Our multivariable model for GOS scores showed that SAPS II, admission category, and vitamin D status remained significantly associated with the 3-month GOS score after we adjusted for other factors (Table 4). Higher SAPS IIs had an OR of 0.925 (95\% CI $0.910-0.940 ; \mathrm{p}<$ $0.001)$, admission for stroke had an OR of 0.409 (95\% CI $0.209-0.803 ; p=0.009$ ), admission for other reasons had an OR of 0.409 (95\% CI 0.217-0.772; $p=0.006$ ), and vitamin D sufficiency had an OR of 1.768 (95\% CI 1.095$2.852 ; \mathrm{p}=0.02)$.

\section{Discussion}

To our knowledge, we present here the first study to examine the role of vitamin $\mathrm{D}$ in postdischarge outcomes in the general neurocritical care population. Our data suggest that patients admitted to our NCCU without vitamin D deficiency were more than 1.7 times more likely to achieve a GOS score of 4 or 5 (moderate or low disability) than those who were deficient in vitamin $\mathrm{D}$.

Increasing evidence has suggested that vitamin $\mathrm{D}$ plays an important role in an array of physiological functions, mediated by a widely distributed nuclear receptor implicated in hundreds of diverse metabolic pathways. ${ }^{5}$ Vitamin D deficiency is common; the overall prevalence was greater than $40 \%$ in 1 recent pooled analysis of multiple European studies ${ }^{4}$ and can be seen in $20 \%-56 \%$ of critically ill patients. ${ }^{29}$ It has been shown to be associated with a number of negative outcomes, including increased risk of death ${ }^{17}$ and higher rates of infection. ${ }^{7}$ Yet there has been a lack of studies investigating the effects of hypovitaminosis D in the neurocritical care population, and to date, no data regarding posthospitalization outcomes in this group have been published. The role that vitamin D plays in the CNS continues to be an area of active investigation. Studies have found that vitamin D receptors are distributed widely in the brain, including the temporal cortex, the thalamus, and the pituitary gland. ${ }^{6}$ These receptors might play a crucial role in a variety of processes, and vitamin D levels have been shown to influence a number of pathways in animal models ranging from the expression of nerve growth factor to the turnover rate of dopamine..$^{10}$

In a 2014 study, Amrein et al. ${ }^{2}$ investigated the effect of vitamin D supplementation on hospital lengths of stay in a randomized controlled trial among critically ill patients. Although no significant benefit with regard to length of stay was found in the supplemented group, a subgroup analysis revealed an improved in-hospital mortality rate for severely deficient subjects $(\leq 12 \mathrm{ng} / \mathrm{ml})$. Our results, 
TABLE 2. Univariate analysis comparing patients who were severely 25-hydroxy vitamin $D$ deficient with those who were 25-hydroxy vitamin $D$ deficient or sufficient

\begin{tabular}{|c|c|c|c|}
\hline Variable & $\begin{array}{c}\text { Severely } \\
\text { Deficient } \\
(\leq 12 \mathrm{ng} / \mathrm{ml})\end{array}$ & $\begin{array}{l}\text { Deficient } \\
\text { or } \\
\text { Sufficient }\end{array}$ & $\mathrm{p}$ Value \\
\hline No. of patients & 59 & 438 & \\
\hline Age (yrs) & $48.9 \pm 15.2$ & $55.7 \pm 18.0$ & $0.006^{*}$ \\
\hline Sex, female & $30(50.8)$ & $195(44.5)$ & 0.359 \\
\hline Hypertension & $27(45.8)$ & $190(43.4)$ & 0.729 \\
\hline Diabetes & $8(13.6)$ & $69(15.8)$ & 0.662 \\
\hline Tobacco use & $23(39.0)$ & $58(13.2)$ & $<0.001^{*}$ \\
\hline Alcohol use & $20(33.9)$ & $142(32.4)$ & 0.820 \\
\hline Illicit drug use & $6(10.2)$ & $24(5.5)$ & 0.156 \\
\hline Vitamin D supplementation & $2(3.4)$ & $109(24.9)$ & $<0.001^{*}$ \\
\hline SAPS II & $27.3 \pm 18.2$ & $25.7 \pm 15.4$ & 0.447 \\
\hline $\mathrm{BMI}\left(\mathrm{kg} / \mathrm{m}^{2}\right)$ & $30.8 \pm 9.4$ & $28.1 \pm 6.0$ & $0.002^{*}$ \\
\hline $\begin{array}{l}\text { Glomerular filtration rate }(\mathrm{ml} / \\
\left.\qquad \mathrm{min} / 1.73 \mathrm{~m}^{2}\right)\end{array}$ & $92.2 \pm 30.6$ & $87.0 \pm 24.6$ & 0.139 \\
\hline High calcium level & $5(8.5)$ & $70(16.0)$ & 0.130 \\
\hline High phosphate level & $36(61.0)$ & $220(50.2)$ & 0.120 \\
\hline Planned admission & $22(37.3)$ & $159(36.3)$ & 0.882 \\
\hline Surgery during NCCU stay & $32(54.2)$ & $271(61.9)$ & 0.259 \\
\hline Insurance type & & & $0.002^{*}$ \\
\hline Private & $33(55.9)$ & $216(49.3)$ & \\
\hline Medicaid/self-pay & $17(28.8)$ & $68(15.5)$ & \\
\hline Medicare & $9(15.3)$ & $154(35.2)$ & \\
\hline Admission category & & & 0.222 \\
\hline Postop & $20(33.9)$ & $158(36.1)$ & \\
\hline Trauma & $12(20.3)$ & $48(11.0)$ & \\
\hline Stroke & $12(20.3)$ & $106(24.2)$ & \\
\hline Other & $15(25.4)$ & $126(28.8)$ & \\
\hline Race/ethnicity & & & $0.004^{*}$ \\
\hline Caucasian & $44(74.6)$ & $378(86.3)$ & \\
\hline Hispanic/Latino & $6(10.2)$ & $33(7.5)$ & \\
\hline African American & $2(3.4)$ & $3(0.7)$ & \\
\hline Asian/Pacific Islander & $5(8.5)$ & $6(1.4)$ & \\
\hline Native American & $0(0.0)$ & $2(0.5)$ & \\
\hline Other/unknown & $2(3.4)$ & $16(3.7)$ & \\
\hline Length of NCCU stay (days) & $3.6 \pm 4.1$ & $3.8 \pm 5.1$ & 0.683 \\
\hline Length of hospital stay (days) & $7.0 \pm 6.7$ & $6.6 \pm 7.5$ & 0.738 \\
\hline Ventilator duration (days) & $1.8 \pm 4.8$ & $1.3 \pm 4.5$ & 0.415 \\
\hline Urinary tract infection & $4(6.8)$ & $31(7.1)$ & 0.933 \\
\hline Pneumonia & $8(13.6)$ & $22(5.0)$ & $0.010^{*}$ \\
\hline Sepsis & $1(1.7)$ & $4(0.9)$ & 0.572 \\
\hline 30-day readmission & & & 0.062 \\
\hline No & $41(69.5)$ & $360(82.2)$ & \\
\hline Yes & 11 (18.6) & $44(10.0)$ & \\
\hline $\begin{array}{l}\text { Death before } 30 \text { days after } \\
\text { discharge }\end{array}$ & $7(11.9)$ & $34(7.8)$ & \\
\hline
\end{tabular}

CONTINUED IN NEXT COLUMN »

\section{» CONTINUED FROM PREVIOUS COLUMN}

TABLE 2. Univariate analysis comparing patients who were severely 25-hydroxy vitamin $D$ deficient with those who were 25-hydroxy vitamin $D$ deficient or sufficient

\begin{tabular}{lccc}
\hline Variable & $\begin{array}{c}\text { Severely } \\
\text { Deficient } \\
(\leq 12 \mathrm{ng} / \mathrm{ml})\end{array}$ & $\begin{array}{c}\text { Deficient } \\
\text { or } \\
\text { Sufficient }\end{array}$ & p Value \\
\hline 3-mo GOS score & & & 0.059 \\
\hline 1-3 & $23(39.0)$ & $119(27.2)$ & \\
\hline 4-5 & $36(61.0)$ & $319(72.8)$ & \\
\hline 3-mo mortality & $13(22.0)$ & $62(14.2)$ & 0.112 \\
\hline
\end{tabular}

* $p$ values $<0.05$ were considered significant.

combined with the lack of significant adverse events caused by supplementation found in the study by Amrein et al., ${ }^{2}$ suggest that additional well-designed trials into the benefits of vitamin $\mathrm{D}$ supplementation, specifically on postdischarge outcomes in neurocritical care patients, are warranted. We are beginning a randomized clinical trial to evaluate the role of vitamin D supplementation in patients under neurocritical care.

Several limitations exist with our study. The first limitation is that the data were obtained at a single institution, which might limit the data's generalizability; the majority of our patients are Caucasian, and all of them were managed at a quaternary care center. Although our study represents one of the largest to have examined hypovitaminosis D in critically ill patients, it remains possible that it was underpowered to detect more subtle differences between groups. This might be the reason that no difference in 3-month GOS scores was found when the severely deficient subgroup was analyzed, because $<12 \%$ of our cohort was in this category. In addition, our study enrolled a heterogeneous cohort of patients with a variety of neurological and neurosurgical conditions. We attempted to control for this heterogeneity in several ways. Although the number of patients was not large enough to allow for robust analysis of individual pathologies, the division of patients into broad diagnostic categories and the inclusion of these categories in our regression analysis possibly mitigated a degree of confounding. The use of the SAPS II in our regression model also enabled us to control for the level of illness of patients in the comparison groups. Although the SAPS II was developed initially as a predictive tool for in-hospital death, multiple studies have demonstrated its utility in predicting longer-term outcomes in critically ill patients. ${ }^{9,22,24}$ Despite these safeguards, it is possible that other confounders that could skew our results exist. Future studies examining more targeted subgroups of patients under neurocritical care is needed to determine whether certain conditions are affected by hypovitaminosis D more than others are.

The fact that one-third of the patients could not be evaluated for GOS score at the 3-month follow-up visit also represents a major limitation of our analysis, although average vitamin D levels between those included in the study and those who were excluded were not significantly different $(26.3 \pm 12.9$ [included patients] vs $25.5 \pm 13.1$ [exclud- 
TABLE 3. Univariate analysis comparing patients with a low and those with a high 3-month GOS score

\begin{tabular}{|c|c|c|c|}
\hline \multirow[b]{2}{*}{ Variable } & \multicolumn{2}{|c|}{ GOS Score } & \multirow[b]{2}{*}{ p Value } \\
\hline & $1-3$ & $4-5$ & \\
\hline No. of patients & 142 & 355 & \\
\hline Age (yrs) & $60.9 \pm 17.3$ & $52.5 \pm 17.5$ & $<0.001^{*}$ \\
\hline Sex, female & $56(39.4)$ & $169(47.6)$ & 0.098 \\
\hline Hypertension & $72(50.7)$ & $145(40.8)$ & $0.045^{*}$ \\
\hline Diabetes & $32(22.5)$ & $45(12.7)$ & $0.006^{*}$ \\
\hline Tobacco use & $26(18.3)$ & $55(15.5)$ & 0.442 \\
\hline Alcohol use & $37(26.1)$ & $125(35.2)$ & $0.049^{*}$ \\
\hline Illicit drug use & $12(8.5)$ & $18(5.1)$ & 0.153 \\
\hline Vitamin D supplementation & $26(18.3)$ & $85(23.4)$ & 0.173 \\
\hline SAPS II & $38.3 \pm 16.6$ & $20.9 \pm 12.2$ & $<0.001^{*}$ \\
\hline BMI $\left(\mathrm{kg} / \mathrm{m}^{2}\right)$ & $27.4 \pm 6.7$ & $28.8 \pm 6.4$ & $0.034^{*}$ \\
\hline $\begin{array}{l}\text { Glomerular filtration rate }(\mathrm{ml} / \\
\left.\quad \mathrm{min} / 1.73 \mathrm{~m}^{2}\right)\end{array}$ & $83.6 \pm 30.5$ & $89.2 \pm 23.0$ & $0.027^{*}$ \\
\hline Vitamin D deficient & $63(44.4)$ & $119(33.5)$ & $0.023^{*}$ \\
\hline High calcium level & $21(14.8)$ & $54(15.2)$ & 0.905 \\
\hline High phosphate level & $55(38.7)$ & $201(56.6)$ & $<0.001^{*}$ \\
\hline Planned admission & $19(13.4)$ & $162(45.6)$ & $<0.001^{*}$ \\
\hline Surgery during NCCU stay & $61(43.0)$ & $242(68.2)$ & $<0.001^{*}$ \\
\hline Insurance type & & & $<0.001^{*}$ \\
\hline Private & $52(36.6)$ & $197(55.5)$ & \\
\hline Medicaid/self-pay & $27(19.0)$ & $58(16.3)$ & \\
\hline Medicare & $63(44.4)$ & $100(28.2)$ & \\
\hline Admission category & & & $<0.001^{*}$ \\
\hline Postop & $20(14.1)$ & $158(44.5)$ & \\
\hline Trauma & $15(10.6)$ & $45(12.7)$ & \\
\hline Stroke & $56(39.4)$ & $62(17.5)$ & \\
\hline Other & $51(35.9)$ & $90(25.4)$ & \\
\hline Race/ethnicity & & & $0.045^{*}$ \\
\hline Caucasian & $114(80.3)$ & $308(86.8)$ & \\
\hline Hispanic/Latino & $10(7.0)$ & $29(8.2)$ & \\
\hline African American & $4(2.8)$ & $1(0.3)$ & \\
\hline Asian/Pacific Islander & $5(3.5)$ & $6(1.7)$ & \\
\hline Native American & $1(0.7)$ & $1(0.3)$ & \\
\hline Other/unknown & $8(5.6)$ & $10(2.8)$ & \\
\hline Length of NCCU stay (days) & $5.3 \pm 6.5$ & $3.2 \pm 4.1$ & $<0.001^{*}$ \\
\hline Length of hospital stay (days) & $9.1 \pm 10.5$ & $5.7 \pm 5.5$ & $<0.001^{*}$ \\
\hline Ventilator duration (days) & $2.9 \pm 6.6$ & $0.7 \pm 3.2$ & $<0.001^{*}$ \\
\hline Urinary tract infection & $17(12.0)$ & $18(5.1)$ & $0.007^{*}$ \\
\hline Pneumonia & $19(13.4)$ & $11(3.1)$ & $<0.001^{*}$ \\
\hline Sepsis & $2(1.4)$ & $3(0.8)$ & 0.570 \\
\hline
\end{tabular}

* $p$ values $<0.05$ were considered significant.

ed patients]; $p=0.389$ ), which suggests that vitamin $D-d e-$ ficient patients and vitamin D-sufficient patients tended to be excluded unprejudicially. Other variables also did not vary significantly between the included and excluded patients, including age $(54.9 \pm 17.8$ years [included patients] vs $57.1 \pm 18.6$ years [excluded patients]; $p=0.104$ ), SAPS II $(25.9 \pm 15.7$ [included patients] vs $24.6 \pm 13.2$ [excluded
TABLE 4. Binomial logistic regression analysis of factors associated with 3-month GOS scores

\begin{tabular}{ccc}
\hline Variable & OR $(95 \% \mathrm{Cl})$ & $\mathrm{p} \mathrm{Value}$ \\
\hline SAPS II & $0.925(0.910-0.940)$ & $<0.001^{*}$ \\
\hline Admission category & & $0.002^{*}$ \\
\hline Postop & Reference & Reference \\
\hline Trauma & $1.193(0.500-2.842)$ & 0.691 \\
\hline Stroke & $0.409(0.209-0.803)$ & $0.009^{*}$ \\
\hline Other & $0.409(0.217-0.772)$ & $0.006^{*}$ \\
\hline Vitamin D sufficient & $1.768(1.095-2.852)$ & $0.020^{*}$ \\
\hline${ }^{*}$ p values $<0.05$ were considered significant. &
\end{tabular}

patients]; $\mathrm{p}=0.261$ ), and admission category $(35.8 \%$ postoperative, $12.1 \%$ trauma, $23.7 \%$ stroke, and $28.4 \%$ other [included patients] vs $33.1 \%$ postoperative, $17.9 \%$ trauma, $23.6 \%$ stroke, and $25.3 \%$ other [excluded patients]; $\mathrm{p}=$ 0.142). Despite these results, the possibility exists that the absence of available 3-month GOS scores for such a high proportion of our patients had a significant effect on our findings. Providing supplementation for our patients who were found to be deficient in vitamin D might have introduced further confounding into our study, although we would expect that attempts to normalize hypovitaminosis $\mathrm{D}$ would tend to bias us more toward the null hypothesis. We also did not collect vitamin D levels of our patients at follow-up, and future studies would certainly benefit from evaluations of vitamin D level after discharge. Last, the fact that GOS scores were assessed without blinding to vitamin D levels might have biased our results.

\section{Conclusions}

Vitamin D deficiency on admission is associated with a worse 3-month outcome as measured by GOS scores in patients who presented to our NCCU. Because of the design of our study, it is impossible to infer any form of causation in regard to our findings. Although it is possible that such a relationship exists between vitamin $D$ level and 3-month outcome in the neurocritical care population, a well-designed randomized controlled trial to investigate the use of vitamin D supplementation in this subpopulation of critically ill patients is needed before such a determination can be made, and performing such a study should be the next step taken.

\section{References}

1. Al-Badr W, Martin KJ: Vitamin D and kidney disease. Clin J Am Soc Nephrol 3:1555-1560, 2008

2. Amrein K, Schnedl C, Holl A, Riedl R, Christopher KB, Pachler C, et al: Effect of high-dose vitamin D3 on hospital length of stay in critically ill patients with vitamin D deficiency: the VITdAL-ICU randomized clinical trial. JAMA 312:1520-1530, 2014

3. Braun AB, Gibbons FK, Litonjua AA, Giovannucci E, Christopher KB: Low serum 25-hydroxyvitamin D at critical care initiation is associated with increased mortality. Crit Care Med 40:63-72, 2012

4. Cashman KD, Dowling KG, Škrabáková Z, Gonzalez-Gross $M$, Valtueña J, De Henauw S, et al: Vitamin D deficiency in Europe: pandemic? Am J Clin Nutr 103:1033-1044, 2016 
5. Dobnig H: A review of the health consequences of the vitamin D deficiency pandemic. J Neurol Sci 311:15-18, 2011

6. Eyles DW, Smith S, Kinobe R, Hewison M, McGrath JJ: Distribution of the vitamin D receptor and $1 \alpha$-hydroxylase in human brain. J Chem Neuroanat 29:21-30, 2005

7. Flynn L, Zimmerman LH, McNorton K, Dolman M, Tyburski J, Baylor A, et al: Effects of vitamin D deficiency in critically ill surgical patients. Am J Surg 203:379-382, 2012

8. Guan J, Karsy M, Brock AA, Eli IM, Ledyard HK, Hawryluk $\mathrm{GW}$, et al: A prospective analysis of hypovitaminosis D and mortality in 400 patients in the neurocritical care setting. J Neurosurg 127:1-7, 2016

9. Handschu R, Haslbeck M, Hartmann A, Fellgiebel A, Kolominsky-Rabas P, Schneider D, et al: Mortality prediction in critical care for acute stroke: severity of illness-score or coma-scale? J Neurol 252:1249-1254, 2005

10. Harms LR, Burne TH, Eyles DW, McGrath JJ: Vitamin D and the brain. Best Pract Res Clin Endocrinol Metab 25:657-669, 2011

11. Holick MF: Vitamin D status: measurement, interpretation, and clinical application. Ann Epidemiol 19:73-78, 2009

12. Holter JC, Ueland T, Norseth J, Brunborg C, Frøland SS, Husebye E, et al: Vitamin D status and long-term mortality in community-acquired pneumonia: secondary data analysis from a prospective cohort. PLoS One 11:e0158536, 2016

13. Jennett $B$, Bond $M$ : Assessment of outcome after severe brain damage. Lancet 1:480-484, 1975

14. Latimer CS, Brewer LD, Searcy JL, Chen KC, Popović J, Kraner SD, et al: Vitamin D prevents cognitive decline and enhances hippocampal synaptic function in aging rats. Proc Natl Acad Sci U S A 111:E4359-E4366, 2014

15. Le Gall JR, Lemeshow S, Saulnier F: A new Simplified Acute Physiology Score (SAPS II) based on a European/ North American multicenter study. JAMA 270:2957-2963, 1993

16. Levey AS, Stevens LA, Schmid CH, Zhang YL, Castro AF III, Feldman HI, et al: A new equation to estimate glomerular filtration rate. Ann Intern Med 150:604-612, 2009

17. Lucidarme O, Messai E, Mazzoni T, Arcade M, du Cheyron $\mathrm{D}$ : Incidence and risk factors of vitamin D deficiency in critically ill patients: results from a prospective observational study. Intensive Care Med 36:1609-1611, 2010

18. Malabanan A, Veronikis IE, Holick MF: Redefining vitamin D insufficiency. Lancet 351:805-806, 1998

19. Moon BH, Park SK, Jang DK, Jang KS, Kim JT, Han YM: Use of APACHE II and SAPS II to predict mortality for hemorrhagic and ischemic stroke patients. J Clin Neurosci 22:111-115, 2015

20. Park SK, Chun HJ, Kim DW, Im TH, Hong HJ, Yi HJ: Acute Physiology and Chronic Health Evaluation II and Simplified Acute Physiology Score II in predicting hospital mortality of neurosurgical intensive care unit patients. J Korean Med Sci 24:420-426, 2009

21. Pincus $\mathrm{M}, \mathrm{Abraham} \mathrm{N}$ Jr: Interpreting laboratory results, in McPherson R, Pincus M (eds): Henry's Clinical Diagnosis and Management by Laboratory Methods, ed 22. Philadelphia: Saunders, 2011

22. Raj R, Skrifvars M, Bendel S, Selander T, Kivisaari R, Siironen J, et al: Predicting six-month mortality of patients with traumatic brain injury: usefulness of common intensive care severity scores. Crit Care 18:R60, 2014

23. Ravindra VM, Godzik J, Guan J, Dailey AT, Schmidt MH, Bisson EF, et al: Prevalence of Vitamin D deficiency in patients undergoing elective spine surgery: a cross-sectional analysis. World Neurosurg 83:1114-1119, 2015

24. Roch A, Wiramus S, Pauly V, Forel JM, Guervilly C, Gainnier $\mathrm{M}$, et al: Long-term outcome in medical patients aged 80 or over following admission to an intensive care unit. Crit Care 15:R36, 2011

25. Rosen CJ: Clinical practice. Vitamin D insufficiency. N Engl J Med 364:248-254, 2011

26. Ross AC, Taylor CL, Yaktine AL, Del Valle HB (eds): Dietary Reference Intakes for Calcium and Vitamin D. Washington, DC: National Academies Press, 2011

27. Schlögl M, Holick MF: Vitamin D and neurocognitive function. Clin Interv Aging 9:559-568, 2014

28. Schuiling WJ, de Weerd AW, Dennesen PJ, Algra A, Rinkel GJ: The simplified acute physiology score to predict outcome in patients with subarachnoid hemorrhage. Neurosurgery 57:230-236, 2005

29. Venkatram S, Chilimuri S, Adrish M, Salako A, Patel M, Diaz-Fuentes G: Vitamin D deficiency is associated with mortality in the medical intensive care unit. Crit Care 15:R292, 2011

30. Zhang YP, Wan YD, Sun TW, Kan QC, Wang LX: Association between vitamin D deficiency and mortality in critically ill adult patients: a meta-analysis of cohort studies. Crit Care 18:684, 2014

\section{Disclosures}

The authors report no conflict of interest concerning the materials or methods used in this study or the findings specified in this paper.

\section{Author Contributions}

Conception and design: Park, Guan, Karsy, Brock, Ledyard, Hawryluk. Acquisition of data: Guan, Karsy, Brock, Eli. Analysis and interpretation of data: Guan. Drafting the article: Park, Guan, Karsy, Brock, Manton, Hawryluk. Critically revising the article: Park, Guan, Karsy, Brock, Manton, Ledyard, Hawryluk. Reviewed submitted version of manuscript: Park, Guan. Approved the final version of the manuscript on behalf of all authors: Park. Statistical analysis: Guan.

\section{Correspondence}

Min S. Park, Department of Neurosurgery, Clinical Neurosciences Center, University of Utah, $175 \mathrm{~N}$ Medical Dr. East, Salt Lake City, UT 84132. email: neuropub@hsc.utah.edu. 